\title{
Treatment of Pharmaceutical Sludge by Fenton Oxidation Process
}

\author{
Rajesh Nithyanandam and Raman Saravanane
}

\begin{abstract}
Fenton Oxidation process was used to treat the pharmaceutical sludge having the COD value of $118,400 \mathrm{mg} / \mathrm{L}$ for the safe disposal. By varying the ratio of ferrous to hydrogen peroxide for different molar ratio $(0.1 \mathrm{M}, 0.2 \mathrm{M}, 0.3 \mathrm{M}, 0.35 \mathrm{M}, 0.4$ M) of Fenton's reagent the pharmaceutical sludge was treated and COD reductions were calculated and optimum ratio was found out. Sludge was also treated by physical treatment by varying the $\mathrm{pH}$ and temperature and $\mathrm{COD}$ reductions were calculated and the optimum point was found out. The untreated and treated sludge was subjected to GC-MS for the quantitative analysis of non-biodegradable compounds. Scanning Electron Microscope image acquistation and elemental analysis were also studied for both treated and untreated samples. The purpose of the study is to find the suitable end-use method for reusing the treated and oxidized products.
\end{abstract}

Index Terms-Antibiotics, chemical treatment, Fenton Oxidation, pharmaceutical sludge.

\section{INTRODUCTION}

Pharmaceutical industry often generates high strength wastewater and sludge changing, in character and quantity depending upon the used manufacturing processes and season [1]. The effluents originated from the formulation of antibiotics have low biodegradability since they contain almost only active substance. As per chemical equilibrium principle, the compounds which are present in effluent will also present in sludge. Hence treatment is necessary for pharmaceutical sludge. Several studies have observed antibiotic agents in the aquatic environment, including groundwater, surface water, and wastewater treatment plant effluent [2]. Despite knowing the sources and pathways of pharmaceuticals into the environment, actual concentrations and availability are unknown. Antibiotics generally have low biodegradability since they are biocidal substances and the degradation of these substances cannot be accomplished in the natural environment or biological treatment plants [3]. Pharmaceuticals released in the environment may impose toxicity virtually on any level of the biological hierarchy, i.e. cells, organs, organisms and population [4]. Hence chemical treatment such as AOP (Advanced Oxidation Process) is necessary.

In recent years, there is a wide concern by Scientist and researchers towards recalcitrant compounds (xenobiotic or non-biodegradable) which is discharged from industry as

Manuscript received July 2, 2013; revised September 10, 2013.

Rajesh Nithyanandam is with the School of Engineering, Taylor's Lakeside Campus, Taylor's University, 47500, Subang Jaya, Selangor, Kuala Lumpur, Malaysia (tel.: + 60 149516037; fax: +6 035629 5477; e-mail: chemrajesh1982@gmail.com).

Raman Saravanane is with the Department of Environmental Engineering Lab, Pondicherry Engineering College, Pondicherry, India. effluent or sludge. The hazardous waste discharged from industries such as pharmaceutical industry is primary concern in the recent decades. In Italy, France, Greece and Sweden different therapeutic pharmaceutical classes were found in the effluent of sewage treatment plant [5].

In spite of the regulations of Environmental Protection Agency (EPA) and Federal Agency, the effluent from industry is not adequately treated [6]. Several methods have been found for treating the recalcitrant compound found in waste water or in sludge. But the methods were found to be ineffective in respect of complying with the final disposal standards. From the literature survey it is very well clear that among Advanced Oxidation Process (AOP), Fenton's reagent is the effective method to treat the recalcitrant compound because the hydroxyl radical formed during the reaction of ferrous sulphate to hydrogen peroxide, have the tendency to degrade the aromatic and heterocyclic ring [7]-[8].

It was found that advanced oxidation had not been widely applied yet because the chemical processes behind advanced oxidation is not completely understood [9]. Specific operating conditions and reactant doses are necessary for complete mineralization of the organics, and for effective wastewater and sludge treatment. AOP is expensive to install and operate; they may be unavoidable for the tertiary treatment of refractory organics present in industrial effluents and sludge to allow safe discharge of industrial contaminants. AOP includes Fenton reagent, $\mathrm{O}_{3}, \mathrm{O}_{3} / \mathrm{H}_{2} \mathrm{O}_{2}, \mathrm{O}_{3} / \mathrm{UV}$.

The application of several AOP has also been tested in some pilot-plant studies. In spite of the enormous physical, chemical and technical knowledge about AOP experts still disagree about the most efficient method for dealing with a specific wastewater problem. Among AOP, Fenton treatment as the following advantages: The Fenton reaction has a short reaction time among all advanced oxidation processes and Iron and $\mathrm{H}_{2} \mathrm{O}_{2}$ are cheap and non-toxic, there is no mass transfer limitations due to its homogenous catalytic nature, there is no energy involved as catalyst and the process is easily to run and control [10].

Fenton treatment, however, appears to be technically very complicated, as the $\mathrm{pH}$ should be near 2 during the reaction, and the dissolved iron has to be precipitated as $\mathrm{Fe}(\mathrm{OH})$, by neutralization at the end of the process. There is evidence that the mechanism of the Fenton reaction is considerably more complicated. However this method is the effective way of treating the recalcitrant compounds. Neyens et al., (2002 \& 2003) studied the effects of $\mathrm{pH}$, temperature, reaction time and $\mathrm{H}_{2} \mathrm{O}_{2}$ concentration with considerable reduction in organic concentration [13].

The objective of the present study is to treat the pharmaceutical sludge by advanced oxidation process using 
Fenton oxidation method. The scope of the study is (a) to find the effective ratio of ferrous to hydrogen peroxide from different molar ratio of Fenton's reagent (b) to find the elemental analysis and the compound degradation, before and after treatment.

\section{MATERIALS AND METHODS}

\section{A. Waste Sludge}

The sludge was collected from the pharmaceutical industry, "Orchid Chemicals and Pharmaceuticals Limited, SIDCO Industrial Estate, Alathur", South India and it was stored in incubator at $4^{\circ} \mathrm{C}$ to avoid biodegradation. It was produced by the pharmaceutical industry from secondary treatment during effluent treatment process. Before analysis, sludge was diluted and used for all the experiments. The experiments were conducted at a room temperature of $35^{\circ} \mathrm{C}$. The sludge was diluted to $25 \%$ by means of distill water. $200 \mathrm{ml}$ of diluted sludge sample was taken in five different canes (5 liters capacity).

\section{B. Fenton Oxidation Experiment}

$200 \mathrm{ml}$ of diluted sludge was poured into the each 5 liter cane. The $\mathrm{pH}$ of the diluted sludge was tested. It is very well clear from the literature Fenton's reaction is optimum at $\mathrm{pH} 2$ to 3 [7]. The diluted sample has the $\mathrm{pH}$ of 7.8. In order to drop the pH from 7.8 to $2-3,20 \mathrm{ml}$ of $20 \% \mathrm{H}_{2} \mathrm{SO}_{4}$ was added. During this addition, the sample raised with bubbles and the $\mathrm{pH}$ was reduced to this range. Afterwards, for 0.1 molar ratio of Fenton reagent, different ratio of ferrous to hydrogen peroxide $(1: 2,1: 4,1: 8,1: 10)$ was added to each cane and allowed to react for half an hour. The $5^{\text {th }}$ cane was used as control to that there is neither addition of sulphuric acid, to control $\mathrm{pH}$, nor Fenton's reagent. This was done to find the normal degradation rate of the compound within half an hour in the atmospheric environment.

After half an hour, sample from each cane was tested for the COD (Chemical Oxygen Demand) reduction and Total solid. COD measurements were used to determine the efficiency of Fenton's Reagent in order to remove the organics during chemical oxidation process.

The same procedure was repeated for different molar ratio of Fenton's Reagent such as 0.2, 0.3, 0.35, and 0.4. The reaction was fast and exothermic, at a room temperature of $35^{\circ} \mathrm{C}$. The aqueous solution of Fenton reagent and diluted sample was stirred during the reaction period of 30 minutes. At the end of half an hour the samples were withdrawn and COD was determined immediately.

\section{Sample Preparation Procedure for GC-MS}

$2 \mathrm{ml}$ of $25 \%$ diluted sludge was taken in a test tube. $0.05 \mathrm{~N}$ of $\mathrm{NaSO}_{4}(2 \mathrm{ml})$ was added to remove the moisture content. Sample was kept for 1 day. Then the sample was centrifuged. Settled particles were subjected to high pressure vacuum filter. Settled particles were kept at $-17^{\circ} \mathrm{C}$ (snow) for $15 \mathrm{~min}$ and then they were subjected to high pressure vacuum filter. Then the moisture less compound was subject to the addition of methanol $(2 \mathrm{ml})$. Finally, the solution was centrifuged at $11000 \mathrm{rpm}$ for $20 \mathrm{~min}$. Supernatant was taken and subject to FID (Flame ionization detector) and GC-MS (AGILENT Technologies; Make: JEOL GC mate; S1.No.6890N).

\section{Scanning Electron Microscope}

For SEM ,the liquid sample was first soaked in phosphate buffered $6 \%$ glutaraldehyde for 1 hour and at less than $20^{\circ} \mathrm{C}$, washed with phosphate buffer and dehydrated with acetone. Then these samples were mounted on a sample stub and cooled with Gold (200 $\mathrm{A}^{\circ}$ thick) in a sputter coating unit. (Ion sputtering device IPC 1100E, Japan). The samples were then Scanned using SEM (JOEL-JSM 5300, Japan) at a resolution of $4.5 \mathrm{~nm}$ at $30 \mathrm{KVA}$ at a working distance of $8 \mathrm{~mm}$.

\section{E. Elemental Analyzer}

$\mathrm{X}$-ray fluorescence analysis was used to determine the elements of the sample. Rhodium was used as the standard anode material. The tube and generator were designed for a permanent output of $4 \mathrm{~kW}$. The detector was scintillation counter and proportional counter. A $0.077^{\circ}$ collimator was used for high resolution measurements with $\mathrm{LiF}$.

\section{F. Variation of $\mathrm{pH}$ and Temperature}

$1 \mathrm{ml}$ of the sludge was taken and it was diluted to $100 \mathrm{ml}$ distill water to get $1 \%$ dilution. From that $10 \mathrm{ml}$ was taken and it was diluted to $100 \mathrm{ml}$ to get $0.1 \%$ dilution. The $100 \mathrm{ml}$ solution was subject to the addition of $1 \% \mathrm{H}_{2} \mathrm{SO}_{4}$ to attain the $\mathrm{pH}$ of 2.5 . Then the solution was heated to $37^{\circ} \mathrm{C}, 42^{\circ} \mathrm{C}, 47^{\circ} \mathrm{C}$, and $50{ }^{\circ} \mathrm{C}$ respectively. For different temperature COD value was determined. The same procedure was repeated for $\mathrm{pH} 4$ and 6. For increase the $\mathrm{pH}$ to alkaline condition $\mathrm{pH}$ buffer 9.2 solutions ( 1 tablet $/ 100 \mathrm{ml}$ ) was added and the same procedure was repeated for the determination of COD at different temperature. Without changing the $\mathrm{pH}$, the $0.1 \%$ diluted sample $(\mathrm{pH}=7.1$ ) was subject to different temperature and COD was determined.

\section{RESUlTS AND DiSCUSSION}

\section{A. Characterization of Pharmaceutical Effluent Plant Sludge}

Table I presents the characterization of secondary pharmaceutical waste sludge from Orchid Pharmaceutical Effluent treatment Plant.

TABLE I: CHARACTERIZATION OF SECONDARY PHARMACEUTICAL WASTE SLUDGE WITH $25 \%$ DILUTION

\begin{tabular}{|c|l|c|}
\hline $\begin{array}{c}\text { S. } \\
\text { No }\end{array}$ & Characteristics & Values \\
\hline 1 & $\mathrm{pH}$ & 7.8 \\
\hline 2 & Electrical Conductivity, mS/cm & 5.13 \\
\hline 3 & Alkalinity, mg/L & 7721.4 \\
\hline 4 & Total solids, mg/L & 302900 \\
\hline 5 & Total Dissolved Solids, mg/L & 6650 \\
\hline 6 & Total Suspended solids, mg/L & 296250 \\
\hline 7 & Total Volatile Solids, mg/L & 76200 \\
\hline 8 & Total Volatile suspended Solids, mg/L & 75100 \\
\hline 9 & Total Chemical Oxygen Demand, mg/L & 118400 \\
\hline 10 & Soluble Chemical Oxygen Demand, mg/L & 16000 \\
\hline 11 & Volatile Fatty Acid, mg/L & 1380 \\
\hline 12 & Total Kjeldahl Nitrogen, mg/L & 1014 \\
\hline 13 & Phosphorus, mg/L & 5900 \\
\hline 14 & Specific gravity at 32 ${ }^{\circ}$ c, mg/L & 1.106 \\
\hline 15 & Biochemical Oxygen Demand, mg/L & - \\
\hline 16 & Alkalinity/VFA & 5.6 \\
\hline
\end{tabular}




\section{B. COD and Total Solid Variation for Different Molar} Ratio of Fenton Reagent at Different Ratio of $\mathrm{Fe}^{2+} / \mathrm{H}_{2} \mathrm{O}_{2}$

Pharmaceutical sludge was treated with different molar ratio of Fenton Reagent for 30 minutes. During the treatment of sample with $0.1 \mathrm{M}$ of Fenton reagent the foam generated in the cane is very less when compared to the higher molar ratio of Fenton reagent (Fig. 1). At $0.1 \mathrm{M}$ of Fenton reagent, COD is increased drastically, when compared to the original sample. This implies generation of hydroxyl radical is not sufficient at this molar ratio and COD is contributed by ferrous sulphate and hydrogen peroxide as well. Total solid is minimum at 1:8, when compared to the other results.

At $0.2 \mathrm{M}$ of Fenton reagent, COD reduction is not appreciable because it is slightly higher than that of original sample but COD values are lesser than $0.1 \mathrm{M}$ concentration of Fenton reagent. Among all the canes the foam generated in $1: 8$ cane is more. When compared to the other ratios of ferrous to hydrogen peroxide $(1: 2,1: 4$ and 1:10) COD is minimum for $1: 8$. Total solids were minimum value at $1: 8$.

\section{COD and Total Solid Variation for Different Molar} Ratio of Fenton Reagent at Different Ratio of $\mathrm{Fe}^{2+} / \mathrm{H}_{2} \mathrm{O}_{2}$

Pharmaceutical sludge was treated with different molar ratio of Fenton Reagent for 30 minutes. During the treatment of sample with $0.1 \mathrm{M}$ of Fenton reagent the foam generated in the cane is very less when compared to the higher molar ratio of Fenton reagent (Fig. 1). At $0.1 \mathrm{M}$ of Fenton reagent, COD is increased drastically, when compared to the original sample. This implies generation of hydroxyl radical is not sufficient at this molar ratio and COD is contributed by ferrous sulphate and hydrogen peroxide as well. Total solid is minimum at 1:8, when compared to the other results.

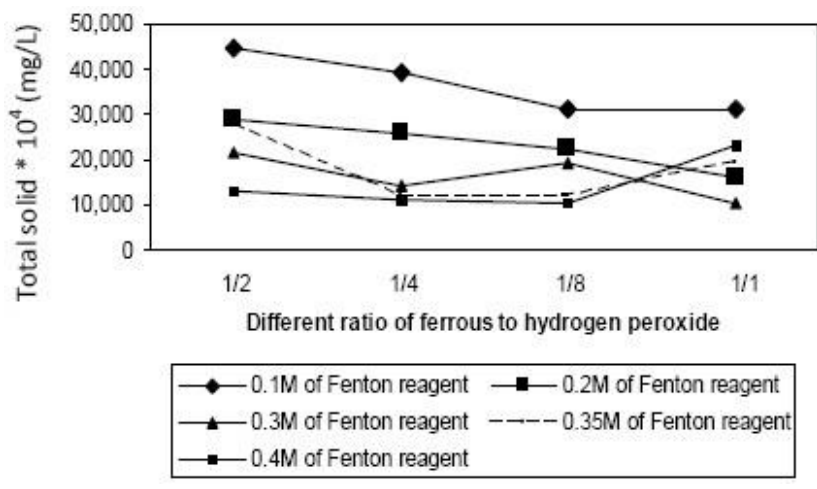

Fig. 1. COD reduction for different ratio of $\mathrm{Fe}^{2+} / \mathrm{H}_{2} \mathrm{O}_{2}$ at different molar ratio.

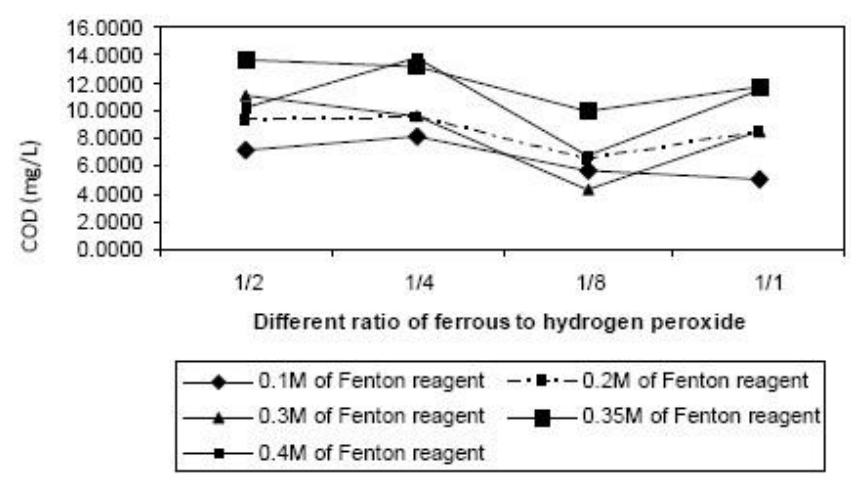

Fig. 2. Total solid reduction for different ratio of $\mathrm{Fe}^{2+} / \mathrm{H}_{2} \mathrm{O}_{2}$ at different molar ratio.
At $0.2 \mathrm{M}$ of Fenton reagent, COD reduction is not appreciable because it is slightly higher than that of original sample but COD values are lesser than $0.1 \mathrm{M}$ concentration of Fenton reagent. Among all the canes the foam generated in $1: 8$ cane is more. When compared to the other ratios of ferrous to hydrogen peroxide $(1: 2,1: 4$ and 1:10) COD is minimum for $1: 8$. Total solids were minimum value at $1: 8$.

At $0.3 \mathrm{M}$ the foam generation is large in all the ratios of ferrous to hydrogen peroxide. Especially at 1:8 \&1:10 the foam generated is maximum. The COD reduction is maximum in 1:10 ratio of ferrous to hydrogen peroxide. Nearly $65 \%$ of COD reduction is achieved in this ratio. In 1:8 ratio COD reduction is nearly about $35 \%$ only. Total solid is minimum at 1:8, when compared to the other results. For the control COD reduction is only $3 \%$.

At $0.35 \mathrm{M}$ ratio of $\mathrm{Fe}^{2+} / \mathrm{H}_{2} \mathrm{O}_{2}$ the $\mathrm{COD}$ reduction is maximum at 1:4 \& 1:8 .But Total solid is minimum at 1:8 only. Nearly $60 \%$ of COD is reduced at $1: 4 \& 1: 8$. At 1:10 COD reduction is only $35 \%$. During hydrogen peroxide consumption at 1:8 \&1:10 the foam generated is maximum and lot of heat energy is generated, it shows the reaction is exothermic. At 1:10 COD value is higher than that of 1:8. This is because large amount of generation of hydroxyl radical consume dissolved oxygen in the sample. The production of hydroxyl radical within a short period of time results in the depletion of dissolved oxygen and this may reduce the efficiency of the mineralization of organics [14]. By comparing the results of $0.1 \mathrm{M}, 0.2 \mathrm{M}, 0.3 \mathrm{M} \& 0.35 \mathrm{M}$ for a particular ratio of ferrous to hydrogen peroxide COD is reduced drastically. This implies higher the molar ratio COD reduction is maximum [15]-[16].

\section{Sludge Characteristic Analysis Before and After Treatment}

TABLE II: SLUDGE CHARACTERISTIC BEFORE AND AFTER TREATMENT

\begin{tabular}{|l|l|l|l|}
\hline S.NO. & Characteristic & $\begin{array}{l}\text { Sludge (before } \\
\text { treatment) }\end{array}$ & $\begin{array}{l}\text { Sludge (after } \\
\text { treatment) }\end{array}$ \\
\hline 1 & COD & 29600 & 10400 \\
\hline 2 & Volatile fatty acids & 840 & 1680 \\
\hline 3 & Phosphate & 226750 & 148750 \\
\hline 4 & Total Solid & 121400 & 253350 \\
\hline 5 & Total Volatile Solid & 29100 & 172650 \\
\hline 6 & Fixed Solid & 92300 & 80700 \\
\hline 7 & Total Dissolved solid & 1850 & 4950 \\
\hline 8 & $\begin{array}{l}\text { Total dissolved volatile } \\
\text { solid }\end{array}$ & 1550 & 2600 \\
\hline 9 & Total suspended solid & 119550 & 248400 \\
\hline 10 & $\begin{array}{l}\text { Volatile suspended } \\
\text { solid }\end{array}$ & 27550 & 170050 \\
\hline
\end{tabular}

$25 \%$ diluted sludge was taken and subject to various characteristic analysis before and after treatment. From the results it was clear that there is a drastic reduction in COD, Phosphate, and Fixed solid. On the same time Total solid, total volatile Solid increases rapidly. Increase in the Value of Total solid is due to addition of Fenton reagent (Ferrous sulphate).That can be reduced by further treatment. The ultimate aim is to reduce the COD value that was achieved by this process (48\% reduction) [17].

\section{E. GC-MS Analysis for Treated and Untreated Sample}

From the chromatogram plots (not shown) it was found that 4 compounds are present for untreated sample by four different peaks. The peaks of different retention time 
indicates different individual compound. From GC-MS all the four compounds was found. The retention time of 4.591 minutes indicates the compound 1,4 benzene dicarboxylic acid. The retention time of 5.442, 7.352, and 8.21 minutes indicates the compound Benzene 1, 1' (bromo methylene) bis, phenylthioacetic acid and phenyl 3- pyridyl ketone respectively. There is only one peak for treated sample that indicates that the other three compounds were degraded by Fenton process. From the chromatogram plots it was clear that the compound having the retention time of 8.21 minutes is not degraded fully. But mostly it was degraded and it was up to the disposal limit.

By GC-MS technique the compounds which were present before and after treatment was found out. By the above technique it was sustain that COD value of the sample is high due to all the four recalcitrant compounds.

\section{F. SEM and Elemental Analysis for Fenton Treated (Optimum) Sample}

From the elemental analysis it was clear that the elements which are present considerably more is oxygen, iron, Phosphorus and Molybdenum. It was clear that iron content was increased drastically from $6 \%$ (by weight) to $28.12 \%$ (by weight) due to Ferrous sulphate. The iron content was reduced by treating the Fenton treated sample with sodium hydroxide. Hence further treatment is necessary. This is the main disadvantage of this process.

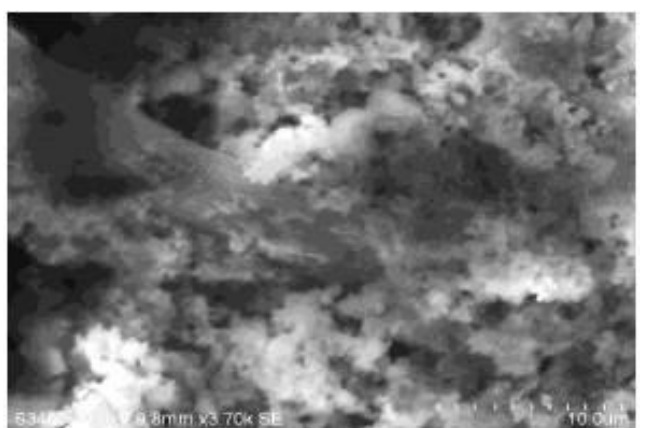

Fig. 3. Image acquistation for Fenton treated sample

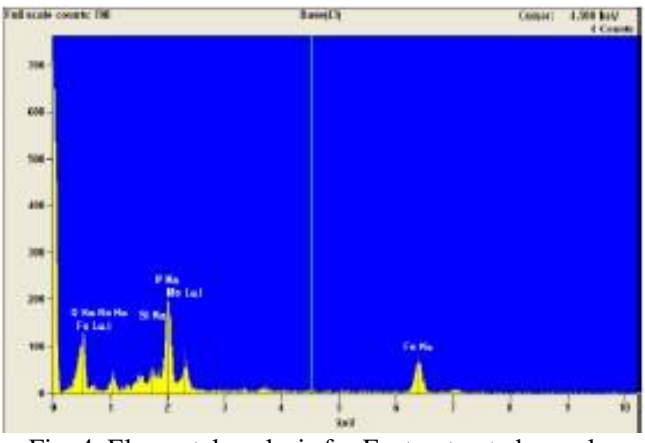

Fig. 4. Elemental analysis for Fenton treated sample

TABLE III: ELEMENTAL ANALYSIS FOR FENTON TREATED SAMPLE

\begin{tabular}{crrrr} 
Element & $\begin{array}{c}\text { Net } \\
\text { Counts }\end{array}$ & K-Ratio & Weight \% & $\begin{array}{c}\text { Atom \% } \\
\text { Error }\end{array}$ \\
\hline $\boldsymbol{O}$ & 1032 & 0.214 & 34.26 & $+/-3.33$ \\
$\mathbf{N a}$ & 368 & 0.041 & 6.94 & $+/-0.80$ \\
$\mathbf{S i}$ & 245 & 0.021 & 1.83 & $+/-0.25$ \\
$\mathbf{P}$ & 2014 & 0.207 & 16.76 & $+/-0.77$ \\
$\mathbf{F e}$ & 1208 & 0.384 & 28.12 & $+/-0.56$ \\
Mo & 970 & 0.133 & 12.09 & $+/-0.38$ \\
Total & & & 100.00 & \\
\hline
\end{tabular}

\section{G. SEM for $\mathrm{pH}$ and Temperature Optimum Variation Sample}

From the elemental analysis of $\mathrm{pH}$ and Temperature variation sample it was found that the oxygen element is found to be more. It was clear that there is no further treatment necessary. But considerable amount of carbon is present here.

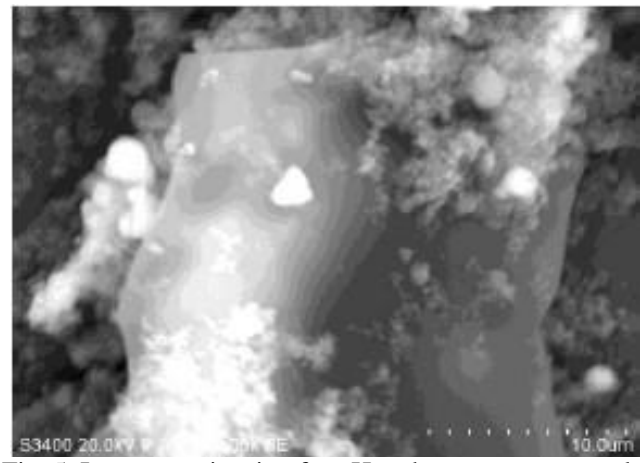

Fig. 5. Image acquistation for $\mathrm{pH}$ and temperature sample

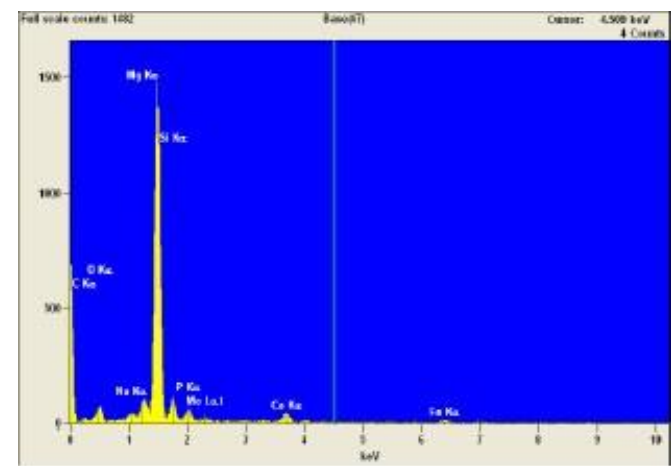

Fig. 6. Elemental analysis for $\mathrm{pH}$ and temperature variation sample

TABLE IV: ELEMENTAL ANALYSIS FOR PH AND TEMPERATURE VARIATION

\begin{tabular}{crrrr} 
Element & $\begin{array}{c}\text { Net } \\
\text { Counts }\end{array}$ & K-Ratio & Weight \% & $\begin{array}{c}\text { Atom \% } \\
\text { Error }\end{array}$ \\
\hline $\boldsymbol{C}$ & 105 & 0.132 & 25.37 & $+/-7.06$ \\
$\boldsymbol{O}$ & 573 & 0.199 & 35.37 & $+/-2.92$ \\
$\mathbf{M g}$ & 493 & 0.062 & 4.64 & $+/-0.34$ \\
$\mathbf{S i}$ & 1186 & 0.172 & 10.04 & $+/-0.25$ \\
$\boldsymbol{P}$ & 534 & 0.092 & 5.53 & $+/-0.22$ \\
$\mathbf{C a}$ & 581 & 0.157 & 8.10 & $+/-0.36$ \\
Fe & 217 & 0.115 & 6.45 & $+/-0.28$ \\
Mo & 308 & 0.071 & 4.49 & $+/-0.13$ \\
Total & & & 100.00 & \\
\hline
\end{tabular}

\section{H. COD Variation by Varying $\mathrm{pH}$ and Temperature}

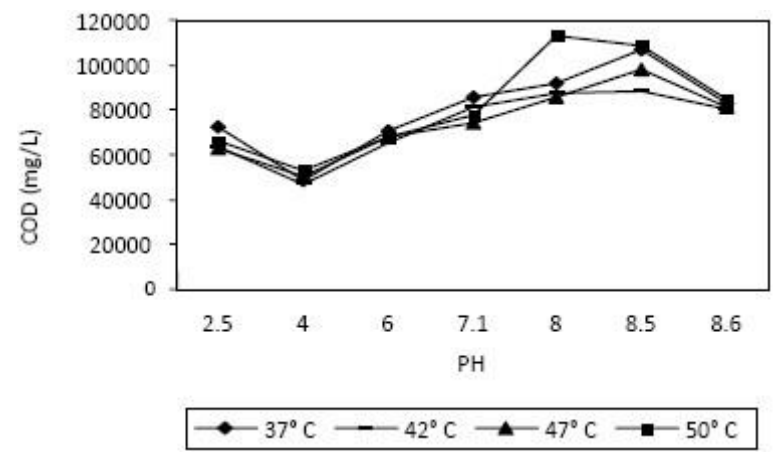

Fig.7. COD variation for different $\mathrm{pH}$ and temperature. 
By varying $\mathrm{pH}$ and Temperature it was found that at $\mathrm{pH} 4$ and $42^{\circ} \mathrm{C}$ COD reduction was maximum, nearly $48 \%$ reduction was achieved. At room temperature by just varying $\mathrm{pH}$ alone it was found that $\mathrm{COD}$ reduction was maximum at $\mathrm{pH} 4$.

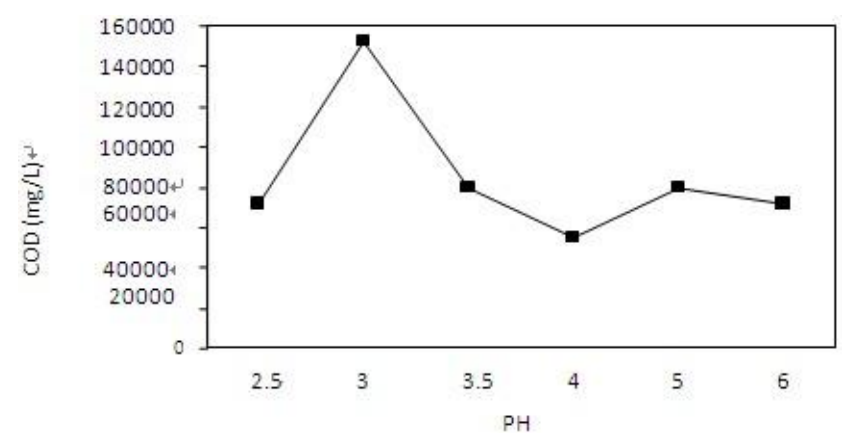

Fig. 8. COD variation for different $\mathrm{pH}$ at room temperature.

\section{CONCLUSIONS}

The hydroxyl radical formed during the reaction is efficiently degrading the antibiotic which is present in the sample, within the detention time of half an hour. For different ratio of ferrous to hydrogen peroxide $(1: 2,1: 4,1: 8$, $1: 10)$ in different molar ratio of Fenton's reagent $(0.1 \mathrm{M}, 0.2 \mathrm{M}$, $0.3 \mathrm{M}, 0.35 \mathrm{M}, 0.4 \mathrm{M})$ the COD reduction was determined. It has been found that COD reduction is maximum in 1:10 ratio of ferrous to hydrogen peroxide at $0.3 \mathrm{M}$ of Fenton's reagent. In this ratio nearly $65 \%$ reduction in COD was achieved. In the same ratio Total solid was also minimum. From the GC-MS results it was found that the compounds like 1, 4 benzene dicarboxylic acid, Benzene 1, 1' (bromo methylene) bis and phenylthioacetic acid were removed totally after treatment. The compound phenyl 3- pyridyl ketone was removed mostly after treatment. And by physical treatment, varying the $\mathrm{pH}$ and Temperature, it was found that COD is minimum at $\mathrm{pH}=4$ and $\mathrm{T}=42^{\circ} \mathrm{C}$. At this critical point $48 \%$ COD reduction was achieved, without adding any chemicals.

From SEM, elemental analysis was found for both Fenton (optimum ratio) treated sample as well as optimum $\mathrm{pH}$ and Temperature variation sample. The antibiotic which is present in the sludge is 7Amino cephalosporanic Acid (7ACA) which is the intermediate of cephalosporin $\mathrm{C}$, which is determined by HPLC. And the further study is needed to determine the degradation pathway of 7 ACA by Fenton process.

\section{ACKNOWLEDGEMENTS}

This research work has been supported by the Pondicherry University-Chemistry Department and Biotechnology Department which are gratefully acknowledged.

\section{NOMENCLATURE}

GC-MS: Gas chromatography - mass spectroscopy

COD: Chemical oxygen demand

SEM: Scanning electron microscope

7ACA: 7Amino cephalosporanic acid

\section{REFERENCES}

[1] N. L. Nemerow, Industrial Water Pollution: Origins, Characters and Treatment, New York: Addison-Wesley Publishing Company, 1978.

[2] T. A. Ternes, M. Stumpf, B. Schuppert, and K. Haberer, "Simultaneous Determination of antiseptics and acidic drugs in sewage and river water," Vom Wasser, vol. 90, pp. 295-309, 1998.

[3] K. Kummererr, Pharmaceuticals in the Environment: Sources, Fate, Effects and Risks, 1 st edition, springer-verlang Berlin Heidelberg, Germany, 2001.

[4] M. Klavarioti, D. Mantzavinos, and D. Kassinos, "Removal of residual pharmaceuticals from aqueous systems by advanced oxidation processes," Environment International, vol. 35, pp. 402-417, 2009.

[5] I. Oller, S. Malato, and J. A. S. Perez, "Combination of Advanced Oxidation Processes and biological treatments for wastewater decontamination - A Review," Science of the Total Environment, vol. 409, pp. 4141-4166, 2011.

[6] Ministry of Environment and Forest, Government of India. [Online]. Available:

http://envfor.nic.in/downloads/public-information/revised-cetp.pdf

[7] Wastewater Engineering Treatment and Reuse by Metcalf and Eddy, $4^{\text {th }}$ Edition, 2003, McGraw Hill Publication.

[8] M. I. Badawy, R. Wahaab, A. S. E. Kalliny, "Fenton-biological treatment processes for the removal of some pharmaceuticals from industrial wastewater," Journal of Hazardous Materials, vol. 167, pp. 567-574, 2009.

[9] J. Bergendahl and J. Shaughnessy. Applications of Advanced Oxidation for wastewater treatment. [Online]. Available: http://www.wpi.edu/Images/CMS/ NEABC/wastewatersummary.pdf

[10] J. D. Rathod, R. N. Shukla, and D. M. Singh, "Combination of advanced oxidation process and biological treatment of industrial wastewater," International Journal of Scientific Engineering and Technology, vol. 1, no. 3, pp. 24-28, 2012.

[11] E. Neyens, J. Baeyens, M. Weemaes, and B. D. Heyder, "Advanced biosolids treatment using $\mathrm{H}_{2} \mathrm{O}_{2}$-oxidation," Environmental Engineering Science, vol. 19, no. 1, pp. 27-35, 2002.

[12] E. Neyens and J. Baeyens, "A review of thermal sludge pre-treatment processes to improve dewaterability," Journal of Hazardous Materials, vol. 98 , pp. 51-67, 2003.

[13] D. P. Mohapatra, S. K. Brar, R. D. Tyagi, and R. Y. Surampalli, "Physico-chemical pre-treatment and biotransformation of wastewater and wastewater sludge - Fate of bisphenol A. Chemosphere," vol. 78, pp. 923-941, 2010

[14] L. Yoon, Y. Lee, and L. Kim, "Investigation of the reaction pathway of $\mathrm{OH}$ radicals produced by Fenton oxidation in the conditions of waste water treatment," Water Science and Technology, vol. 44, no. 5, pp. 15-21, 2001.

[15] R. R. Nithyanandam and R. Saravanane, "Advanced Oxidation Process for the Treatment and Reuse of Refractory Organics," Proceedings of International Interdisciplinary Conference of Sustainable Technologies for Environmental Protection (ICSTEP-2006), Coimbatore, India, 2006.

[16] R. R. Nithyanandam and R. Saravanane, "Fenton Oxidation for the Conversion of Recalcitrant Organic Compounds in Pharmaceutical Sludge," in Proceedings of International Conference on Cleaner Technologies and Environmental Management, Puducherry, India, 2007.

[17] N. S. S. Martinez, J. F. Fernandez, X. F. Segura, and A. S. Ferrer, "Pre-oxidation of an extremely polluted industrial wastewater by the Fenton's reagent," Journal of Hazardous Materials, vol. B101, pp. 315-322, 2003.

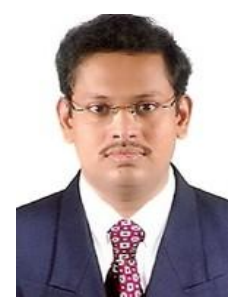

Rajesh Nithyanandam was born in India at Karaikal (Puducherry Union Territory) on $27^{\text {th }}$ July 1982 . He completed his undergraduate in Chemical Engineering from Central Government University (Pondicherry University) in 2004. He continued his higher education and graduated in 2006 as master in Environmental Engineer from the same reputed Institution. After 2 years of work experience, he started his research under Prof. Dr. Duduku Krishnaiah (Ph.D, IIT Mumbai) as

Research fellow (Ph.D) in Chemical Engineering (Food and Bioproducts Processing) in Universiti Malaysia Sabah. He successfully completed his aspiration in November, 2011.

Because of his thirst of knowledge that brought him after Master degree to Central Government of India, NEERI, CSIR (National Environmental Engineering Research Institute, Council of Scientific Industrial Research) as research assistant. He served there until 2007 July. Then he joined a private consultation firm, clean technologies at Bangalore as senior Environmental 
Engineer for a period of one year. During his research period, he published impact factor journals, and attended many International and National conferences. One of his publications, titled "A review of the antioxidant potential of medicinal plant species" (Journal of Food and Bioproducts Processing) is listed in Science direct as top 1 hottest article for a period of 2 years. Another remarkable publication is on the title, "Microencapsulation of Morinda Citrifolia L. fruit extract by spray drying (Journal of Chemical Engineering Research and Design) is also listed in Science direct in top 25 hottest articles for the assess year of 2012. He also published one book chapter in "Phytochemicals" published by European publisher (In-Tech Publisher, 2011). Currently, he is affiliated to Taylor's University and working as Lecturer. His area of expertise is Wastewater Management, Air Pollution Control, Process Integration and Unit Operations, Mass Transfer, Food and Bioproducts Processing and Reaction Engineering.

Dr. Nithyanandam won aspiration award organized by Centre for Post Graduate Studies, Universiti Malaysia Sabah, East Malaysia. He also awarded bronze medal for his publication in the same institution organized by Post Graduate Research and Innovation. 